\title{
O SENTIDO NO TRABALHO DE ENFERMAGEM: CONSTITUINTES PARA SAÚDE MENTAL DURANTE PANDEMIA DA COVID-19
}

\author{
Michell Ângelo Marques Araújo' \\ ORCID: 0000-0002-1506-5371 \\ Manuela de Mendonça Figueirêdo Coelho' \\ ORCID: 0000-0001-6182-9486 \\ Rachel Gabriel Bastos Barbosa' \\ ORCID: 0000-0003-4205-6910 \\ Angela Maria Alves e Souza' \\ ORCID: 0000-0002-4746-1870 \\ Roberta Meneses Oliveira' \\ ORCID: 0000-0002-5803-8605 \\ Jamine Borges de Morais' \\ ORCID: 0000-0002-4173-9202
}

\section{' Departamento de Enfermagem da Faculdade de Farmácia, Odontologia e Enfermagem da Universidade Federal do Ceará. Fortaleza, Ceará, Brasil.}

Autor Correspondente: Michell Ângelo Marques Araújo E-mail: michellangelo@ufc.br

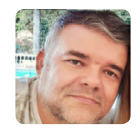

Como citar: Araújo MAM, Coelho MMF, Barbosa RGB, Souza AMA, Oliveira RM, Morais JB. O sentido no trabalho de enfermagem: constituintes para saúde mental durante pandemia da COVID-19. In: Esperidião E, Saidel MGB (Orgs.). Enfermagem em saúde mental e COVID-19. 2.ed.rev. Brasília, DF: Editora ABEn; 2020.

p. 10-16. (Série Enfermagem e Pandemias, 4). https://doi.org/10.51234/aben.20.e04.c01

\section{INTRODUÇÃO}

No ano de 2020, comemora-se o bicentenário do nascimento de Florence Nightingale, precursora da enfermagem moderna. Em paralelo, importante movimento mundial apontou este como o "ano internacional dos profissionais de enfermagem". Tal projeção se deve ao reconhecimento do papel fundamental que a enfermagem desempenha em todos os níveis de atenção à saúde, no mundo inteiro(1)

Ao considerar o trabalho da enfermagem no cuidado à saúde e o papel vital na contemporaneidade, urge discutir o atual cenário de saúde, as implicações dessa categoria, como importante ator social frente ao contexto atual, e os impactos da vivência desse "ser". No final do ano de 2019, nova doença surgiu, em Wuhan, na China, deflagrada pelo coronavírus 2 da Síndrome Respiratória Aguda Grave (Sars-Cov-2), a Coronavirus Disease 2019 (COVID-19). O agravo se espalhou rapidamente, tornando-se pandêmica, logo no início de $2020^{(2)}$.

A pandemia provocou diversas mudanças no modo de viver da população. A velocidade que o vírus é disseminado, associada às altas taxas de mortalidade, à ausência de terapêuticas de sucesso comprovadas e às fragilidades no sistema de saúde brasileiro, levou a população a viver em condições extremas, ainda não vivenciadas na contemporaneidade, como o isolamento social ${ }^{(3)}$.

Mesmo com o afastamento social imposto em grande parte das cidades brasileiras, em meados de junho, a doença já havia acometido mais de um milhão de brasileiros, com taxa de mortalidade de 203,3 óbitos/1.000.000 habitantes, quatro vezes maior que o coeficiente de mortalidade mundial que versa em torno de 54,6 óbitos/ 1.000 .000 de habitantes ${ }^{(4)}$.

Nesse cenário, destaca-se o trabalho da enfermagem, na linha de frente, cuidando de pessoas infectadas e enfrentado as diversas dificuldades impostas pela pandemia. O potencial de infectividade da doença é alto, principalmente nos serviços de saúde, ameaçando, de forma real, os profissionais, tornando-os mais suscetíveis à infecção(5). 
Além das implicações físicas, que impactam diretamente na organização do cuidado, pois a infecção ocasiona o afastamento do profissional, as repercussões emocionais têm sido alvo de reflexões. $\mathrm{O}$ desafio sem precedentes, imposto pela COVID-19, poderá apresentar implicações psíquicas nos trabalhadores da enfermagem que atuam na assistência, as quais ainda não podem ser previstas. Consideram-se que a pressão, a sobrecarga de trabalho e o enfrentamento de tantas mortes possam gerar sofrimento imensurável nesses profissionais, convocando toda a comunidade a refletir sobre os impactos à saúde mental dos profissionais, em meio à pandemia da COVID-19. Deve-se refletir que para além de reconhecer esses trabalhadores como "heróis", deve-se acolher e propiciar fontes de apoio a esses profissionais.

As repercussões da pandemia do COVID-19, junto com todas as situações desfavoráveis do cotidiano do trabalho de enfermagem, aumentam o sofrimento e, por sua vez, podem acarretar, também, muito adoecimento nesses profissionais. Algumas questões em relação à pandemia surgem nesse ínterim: como enfrentar o sofrimento cotidiano nos cuidados de enfermagem? Que estratégia utilizar para manter a saúde mental, diante de situações desfavoráveis no trabalho? Como as implicações do sentido no trabalho de enfermagem podem sustentar a saúde mental desses profissionais?

Refletir e tentar responder a esses questionamentos faz parte do objetivo deste capítulo, com a proposição de Viktor Emil Frankl acerca do "sentido", compreendido como a verdadeira e mais genuína busca do homem, por estar presente em todas as circunstâncias da vida, sendo conduzido por valores para descoberta e vivência do sentido da vida(6).

\section{OBJETIVO}

Refletir sobre a questão do sentido no trabalho de enfermagem, como estratégia para enfrentar o sofrimento cotidiano e manter a saúde mental dos profissionais, em meio à pandemia da COVID-19.

\section{MÉTODO}

Estudo reflexivo, realizado em junho de 2020, em meio à pandemia do COVID-19. As reflexões foram suscitadas a partir de uma revisão narrativa, em que se considerou a situação atual, incluindo os sentidos que permeiam o trabalho de enfermagem e a relação destes com o cotidiano de trabalho, mesmo antes da pandemia. Utilizou-se da análise existencial, de Viktor Emil Frankl, para embasar as reflexões, tendo em vista que este referencial teórico propõe o sentido como parte de toda situação vivenciada pelo ser humano, constituindo-se fenômeno importante.

As reflexões estão apresentadas em três grandes perspectivas de sentido. O sentido expresso em "A Enfermagem como decisão" trata da escolha profissional em meio a afetos, que aproximam e distanciam do cuidado; o segundo, "A Enfermagem e os salários", parte da premissa de que há mais que um salário monetário, há uma remuneração imaterial, que compensa qualquer desvantagem profissional e confere sentido material e simbólico aos enfermeiros; e o terceiro, "A Enfermagem e os enfrentamentos", com foco nas estratégias que podem ser utilizadas para manter a saúde mental desses profissionais.

\section{A ENFERMAGEM COMO DECISÃO}

Compreender a Enfermagem como algo além de uma profissão, talvez ajude a mensurar o esforço, a dedicação e o desgaste a que esses profissionais estão submetidos no fazer cotidiano. A sobrecarga de trabalho, os baixos salários, as condições insalubres, a precarização das relações trabalhistas, a desvalorização social e pouca representatividade política são os principais desafios vivenciados hoje pela Enfermagem. Todas essas questões não são questões vivenciadas somente nesse tempo de pandemia do COVID-19, são agravadas ainda mais, com a quantidade de pessoas que morreram ou foram hospitalizadas, sobrecarregando o sistema de 
saúde e levando, em alguns locais, ao colapso, mas fazem parte de um contexto de sofrimento e adoecimento no trabalho, já por algum tempo descrito ${ }^{(7)}$.

Compreender a Enfermagem como algo além da profissão é reconhecer o caráter de missão e as possibilidades propiciadoras de encontros coexistenciais, que superam as questões psicofísicas de erotismo e apego, configurando-se em um "entrega-se", "oferecer-se", para acolher, cuidar e promover a vida humana, próprias da dimensão espiritual. Esse caráter de missão exige a decisão consciente de quem escolhe tal profissão, para que se realize em plenitude, do contrário, a pessoa que a exerce sem consciência, encher-se-á de ressentimento e frustação, também muito comum em alguns profissionais de enfermagem. Aliado a essa decisão, se vivenciam, no dia a dia de enfermeiro, encontros de vida, próprios de vínculos profundos, advindo da relação profissional-paciente, em que cada um é afetado, de tal maneira, que nunca mais serão os mesmos a partir desse encontro ${ }^{(6)}$.

Os valores vivenciais e criativos são descritos por Frankl como aspectos importantes da vida, em que se pode vivenciar o sentido, não somente na relação estabelecida entre duas pessoas, seja no âmbito pessoal ou profissional, como também com uma instituição ou mesmo uma profissão. Compreendidos esses valores como um comprometer-se com um 'outro', isso é característica própria de uma pessoa adulta e madura, que pode livremente fazer a escolha e arcar com o ônus e o bônus dela. Diante de várias opções, a profissão escolhida passa a ser única, incomparável e insubstituível, descrevendo o que se pode denominar de amor, por esse motivo, é possível dizer que se ama a Enfermagem. Assim, pelos valores vivenciais, personifica-se a profissão e se estabelece relação coexistencial com quem a exerce. Os valores criativos concretizam o sentido, no ato do fazer cotidiano na saúde, podendo ser fator importante para manter a saúde mental do trabalhador, frente ao sofrimento e às dificuldades enfrentadas ${ }^{(6,8)}$.

\section{A ENFERMAGEM E OS SALÁRIOS}

Pode-se refletir: o que faz alguém escolher essa profissão e permanecer nela, diante de tão graves problemas descritos no exercício? Por que não fazer opção por outras profissões, mais valorizadas ou mesmo menos exigentes? O que mantém os profissionais de pé, no sentido físico e mental? A resposta está exatamente no título deste tópico. Sim, é possível optar, permanecer e se realizar profissionalmente, por causa dos salários, ou seja, dos ganhos profissionais, sejam monetários ou afetivos.

Como referido, os salários pagos à categoria não correspondem à importância da profissão e, nem mesmo, aos riscos que ela está submetida. O piso salarial é uma luta que está sendo travada pelas entidades de classe há algum tempo, mas que pouco avança em termos práticos, justamente pela pouca representatividade e articulação política. Por não ser um salário ideal ou mesmo condizente com a profissão, quase sempre o profissional da enfermagem precisa ter mais de um emprego, para que os ganhos monetários permitam não somente sobreviver, mas ter um mínimo de conforto ou dignidade. Nesse aspecto, a questão salarial corresponde a um fator decisivo em relação à saúde mental dos profissionais, uma vez que a sobrecarrega limita o tempo, inclusive de descanso e lazer, aumenta o estresse e põe em risco a própria segurança e a do paciente ${ }^{(1,9)}$.

A pandemia de COVID-19 veio agravar ainda mais a situação, visto que o risco de morte de quem cuida é alto, comprovado pelas centenas de mortes ocorridas em todo o mundo e pelos milhares de infectados. $O$ déficit de enfermeiros era observado em alguns países, mesmo antes da pandemia, isso acontece porque número cada vez mais reduzido de pessoas escolhe essa profissão, sobretudo, nos países mais ricos. Os que ainda escolhem e permanecem, fazem também por um salário afetivo, que seria a satisfação de ajudar o outro, a valorização pessoal da profissão e o caráter de missão na vida, aspectos citados no tópico anterior. Esse salário, de alguma forma, pode compensar o baixo salário monetário e as questões profissionais desfavoráveis. Constata-se que esse salário imprime um sentido, quase incondicional, em que é possível suportar muitas coisas, justamente porque a questão do sentido do trabalho é a chave para compreender a própria existência ${ }^{(3,6,9)}$.

Intitula-se de salário afetivo aquele compreendido como a vivência dos valores criativos e a satisfação que isso proporciona. Descritos por Frankl como capazes de buscar e encontrar o sentido, uma vez que esses 
valores realizam algo significativo para si e para outros, soluciona problemas e deixa um legado, tornando o trabalho rico de sentido. Ter esse entendimento não protege o trabalhador do desgaste, da exaustão e do adoecimento, são necessárias reinvindicações, articulações e negociações por melhores condições, sejam a nível local ou nacional, para que a satisfação da realização profissional venha junto com o reconhecimento financeiro, social e as condições adequadas de trabalho, do contrário, ao invés de se vivenciar o sentido, experimentar-se-ão um sofrimento psíquico e o adoecimento, em consequência ${ }^{(6,13)}$.

\section{A ENFERMAGEM E OS ENFRENTAMENTOS}

O maior desafio enfrentado pelos profissionais de enfermagem, diante da pandemia da COVID-19, é continuar cuidando de pessoas, frente ao risco de infecção de si e dos seus, às condições precárias de assistência, à escassez de leitos de terapia intensiva em relação às demandas e à quantidade de pessoas que morrem todos os dias. Manter-se bem também é desafiador, quando o natural seria desistir desse trabalho penoso, sucumbir ao desespero e ser incapaz de cuidar, mas a vontade de ajudar o outro e a força do sentido desse fazer justificam a perseverança da presença e do protagonismo no cuidado.

Os enfrentamentos necessários nesse contexto são importantes, visto que a situação se configura como sofrimento que foge ao alcance de resolução dos profissionais resolverem. Seria o que Frankl denomina de sofrimento inevitável, ou seja, aquilo que não se pode acabar ou resolver, sendo preciso que se extraia um sentido, uma lição a ser aprendida da situação, até que aconteça uma adaptação. Suportar o sofrimento é possível, quando se encontra um "para quê" da situação, evita-se o desespero e mantêm os níveis aceitáveis de estresse no trabalho, portanto, a saúde mental dos profissionais de enfermagem está diretamente ligada ao sentido que estes encontram na própria situação, até que haja alguma estratégia de resolução ou adaptação. Isto é, a forma como se vivencia a situação adversa consiste em enfrentamentos ${ }^{(6,10)}$.

As formas de enfrentamento possíveis da Enfermagem, que se constituem enquanto caminhos para descoberta e vivência do "sentido", podem ser constituintes para promover e manter a saúde mental dos profissionais, fragmentam-se em três níveis que se instituem de forma isolada, ao mesmo tempo que se consagram em unicidade que sustenta o ser que constitui a Enfermagem (Figura 1).

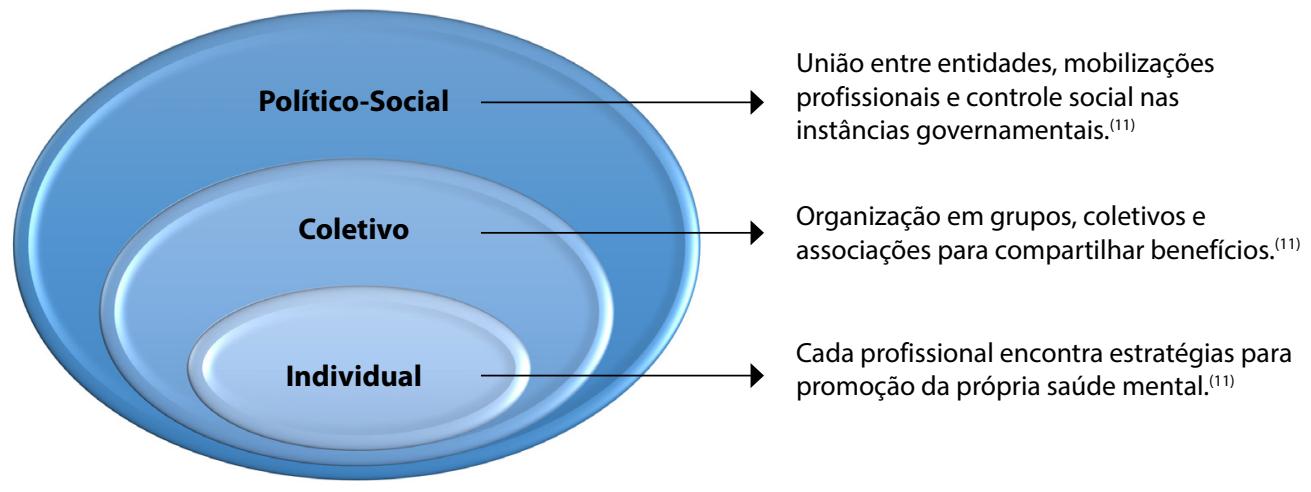

Figura 1 - Níveis de enfrentamento do trabalho de enfermagem, Fortaleza, Brasil,2020

\section{Enfrentamento no nível pessoal}

O autocuidado é importante para o enfrentamento das situações adversas, especialmente em tempo de pandemia, como recomendados: obedecer às normas de segurança para evitar contaminação; reservar tempo para descanso e lazer, em atividades que diminua o estresse e proporcione prazer; manter contato, mesmo que virtual, 
com pessoas queridas e grupos que participava; partilhar francamente com alguém sentimentos - medos, ansiedade, tristeza ou depressão; construir rede de apoio, caso não tenha; praticar atividades integrativas - meditação, yoga, exercícios e outras; procurar psicoterapia, caso tenha necessidade específica ou senta que precisa de ajuda de um profissional. O nível pessoal se constitui espaço de construção de sentido pessoal e inserção do eu no mundo ${ }^{(11)}$.

\section{Enfrentamento no nível coletivo}

Enfrentar qualquer situação junto com um grupo diminui os impactos negativos, uma vez que a partilha com outras pessoas alivia a ansiedade e oferece maior número de estratégias para o enfrentamento. $\mathrm{O}$ empoderamento pessoal é revestido da força do grupo, do sentimento de conjunto e pertença, ao reivindicar e mobilizar outras pessoas para uma causa comum. Fortalece a luta e proporciona momentos de partilha, discussão de saídas do problema, além de favorecer a solidariedade, nos momentos mais difíceis. As entidades de classe surgem nessa perspectiva, para assegurar direitos e dignidade ao trabalhador vinculado, exigindo as condições necessárias e seguras para atuação profissional, bem como oferecer momentos de promoção do bem-estar, que incluem artes, turismo, esporte e cultura (1). Aqui, busca-se o sentido que vai além do "eu", mas de pertença a algo mais, a um todo que sustenta a unidade.

\section{Enfrentamento no nível político-social}

A Enfermagem precisa avançar no enfrentamento no nível mais alto, pois tem maior impacto e pode causar mudanças significativas para profissão como um todo, incluindo a própria saúde mental dos agentes que a compõe. Por ser o maior contingente de profissionais na saúde, tem poder de negociação e reivindicação extraordinário, mas precisa se reconhecer como tal e enfrentar os desafios políticos do setor saúde, especialmente nesse período, cujos holofotes estão sobre a rede de cuidados e o reconhecimento do trabalho realizado na pandemia é observado socialmente. Sair de um discurso individual, avançar para o coletivo e mobilizar-se politicamente são caminhos de enfrentamento que a Enfermagem precisa fazer, do contrário, não progredirá como deseja ou demorará mais tempo do que se espera. Faz parte desse enfrentamento a participação nas políticas de saúde, educação e pesquisa/ ciência, assegurando respectivos desenvolvimentos, evitando retrocessos, participando, sobretudo, na luta contra a privatização do Sistema Único de Saúde ${ }^{(12-13)}$. Constitui-se um sentido ético, um sentido de sociedade, que carece tomar um lugar de fala, um lugar de luta, para construção de um caminho digno para categoria.

Esses enfrentamentos fazem parte da vivência dos valores atitudinais, como descreve Frankl, na análise existencial, são caminhos seguros para o encontro do próprio sentido da vida, uma vez que o sofrimento se reverte de uma motivação de mudança de realidade e construção de novos modelos de atuação e vivências, sendo possível determinar o crescimento pessoal, a partir de uma situação adversa, permeada de desafios e sofrimentos. Portanto, enfrentar as situações mais difíceis, no que tange à saúde da população, faz parte do cotidiano de trabalho da enfermagem e, por conseguinte, importante para o próprio progresso como ciência e profissão, além de contribuir com a promoção da saúde mental desses trabalhadores ${ }^{(10,13)}$.

\section{Limitações}

Por vivenciar, ainda, a pandemia da COVID-19, estudos científicos voltados para saúde mental são limitados, principalmente quando se trata da questão do sentido no trabalho de enfermagem.

\section{Contribuições para Enfermagem}

As reflexões apresentadas dão luz à compreensão do trabalho de enfermagem e da questão do sentido como constituinte de saúde mental dos profissionais. Utilizando-se da análise existencial, de Viktor Emil Frankl, 
como referencial teórico, demonstrou-se a riqueza do fazer cotidiano dos cuidados, permeados de dificuldades e sofrimentos, mas também de ganhos e, ainda mais, de sentido. Destaca-se que as reflexões podem suscitar interesse sobre o assunto e mais produções que abordem o sentido do sofrimento e do trabalho de enfermagem.

\section{CONSIDERAÇÕES FINAIS}

A descoberta e a vivência do sentido do trabalho de enfermagem podem promover a saúde mental dos profissionais, pois o caráter de missão contempla todo um fazer, que inclui o sofrimento, a dor e a morte nesse cotidiano, além disso oportuniza encontros coexistenciais, vividos nas relações enfermeiro-paciente e enfermeiro-Enfermagem. Esse mesmo sentido proporciona um salário imaterial, designado de salário afetivo, rico de sentido e que compensa as desvantagens profissionais e não permite que o profissional desista da profissão e nem sucumba ao desespero e adoecimento. Os enfrentamentos cotidianos, em níveis, também oferecem caminhos à vivência do sentido e torna o cotidiano uma batalha constante para melhorar e fazer progredir a Enfermagem, constituindo, assim, o próprio sentido de ser profissional de enfermagem. Para isso, os valores vivenciais, criativos e atitudinais, descritos por Frankl, são experimentados, promovem e mantêm a saúde mental desses profissionais. Contudo, é preciso reconhecer que estes valores nem sempre são alcançáveis, sendo o sentido a chave para conquista desses princípios, seja do viver, do fazer, ou mesmo, do sofrer.

\section{AGRADECIMENTO}

Ao Departamento de Enfermagem Psiquiátrica e Saúde Mental/Associação Brasileira de Enfermagem (DEPSM/ABEn).

\section{REFERÊNCIAS}

1. COFEN. OMS apoia designar 2020 o ano das enfermeiras obstétricas e parteiras. [Internet] 2020 [cited 2020 Jun 27]. Available from: http://www.cofen.gov.br/oms-apoia-designar-2020-o-ano-das-enfermeiras-obstetricas-e-parteiras_68790.html.

2. National Health Commission of the People's Republic of China. Update on epidemic situation of novel coronavirus-infected pneumonia. [Internet] 2020 [cited 2020 May 30] Available from: http://www.nhc.gov.cn/xcs/ yqfkdt/202002/17a03704a99646ff ad6807bc806f 37a4.shtml.

3. Lyon D. Pandemic Paradox. [Internet] ONF. 2020; 47(4): 371-372. doi: 10.1188/20.0NF.371-372.

4. Ministério da Saúde (BR). Ministério da Saúde. Secretaria de Vigilância em Saúde. Boletim epidemiológico especial - COE - COVID-19. [Intenet]. Brasília: Ministério da Saúde; 2020 [cited 2020 Jun 25]. Available from: http://saude.gov.br/images/ pdf/2020/June/18/Boletim-epidemiologico-COVID-2.pdf.

5. Huang L, Lin G, Tang L, Zhou Z. Special attention to nurses'protection during the COVID-19 epidemic. Critical care. 2020; 24(120):1-3. doi: https://doi.org/10.1186/s13054-020-2841-7.

6. FrankI VE. Logoterapia e Análise Existencial: textos de seis décadas. Ed. Forense Universitária: Rio de Janeiro; 2012.

7. Silva MCN, Machado MH. Sistema de Saúde e Trabalho: desafios para a Enfermagem no Brasil. Ciênc. saúde coletiva [Internet] 2020 [cited 2020 July 01]; 25(1):7-13. Available from: http://www.scielo.br/scielo. php?script=sci_arttext\&pid=S141381232020000100007\&lng=en.Epub Dec 20, 2019. Available from: http://dx.doi. org/10.1590/1413-81232020251.27572019.

8. Cerqueira EK, Vicente RO. The meaning of love in Viktor Frankl's Logotherapy and existential analysis. Studium. [Internet] 2017 [cited 2020 June 30]; 3(4): 26-44. Available from: https://www.faccmt.edu.br/wp-content/uploads/2019/09/SedacRevista-ABRIL-2017.pdf\#page $=26$.

9. Leal JAL, Melo CMM. The nurses' work process in different countries: an integrative review. Rev. Bras. Enferm. [Internet] 2018 [cited 2020 June 30]; 71(2):413-23. Available from: http://www.scielo.br/scielo. php?script=sci_arttext\&pid=S0034716 72018000200413\&lng=en. http://dx.doi.org/10.1590/0034-7167-2016-0468.

10. Aquino TAA, Aquino PLS. Organizational Logotherapy: considerations and possibilities in a university hospital. Logos\&Existência. [Internet] 2015[cited 2020 June 28]; 4 (1): 66-74. Available from: https://periodicos.ufpb.br/index.php/le/ article/view/21430/13067. 
11. Ornell F, Schuch JB, Sordi AO, Kessler FHP. "Pandemic fear” and COVID-19: mental health burden and strategies. Braz. J. Psychiatry [Internet] 2020 [cited 2020 July 01]; 42(3): 232-5. Available from: http://www.scielo.br/scielo.php?script=sci_ arttext\&pid=S1516-44462020000300232\&Ing=en. Epub Apr 03, 2020. http://dx.doi.org/10.1590/1516-4446-2020-0008.

12. Xiang Y-T, Jin Y, Wang Y, Zhang Q, Zhang L, Cheung T. Tribute to health workers in China: A group of respectable population during the outbreak of the COVID-19. Int J Biol Sci. 2020 Mar;16(10)1739-40. doi: 10.7150/ijbs.45135.

13. COVID-19 in Brazil: "So what?" Editorial. The Lancet. [Internet] 2020 [cited 2020 July 01]; 395(9): 1461. Available from: https://www.thelancet.com/pdfs/journals/lancet/PIIS0140-6736(20)31095-3.pdf. 